\title{
Graphical Modification of Text. An Approach To Dyslexic Users.
}

\author{
Tereza Pařilová \\ Faculty of Informatics \\ Masaryk University \\ Botanická 68a, Brno 602 00, Czech Republic \\ parilova@mail.muni.cz
}

\begin{abstract}
The requirements of user interface for dyslexics have not been yet properly explored. Accessibility to any kind of information or just to entertainment web pages is a key factor to equality of rights, moreover it breaks down social barriers. Considering that study materials are nowadays very much accessible through internet, by accommodating web content to anyhow disabled users must be seen as natural thing. Dyslexia is considered as an cognitive impairment arising from visual similarity of letters, therefore we focus on Czech language which uses special characters. The aim of our research is to introduce an application that allows dyslexics to decode text easier and understand it properly.
\end{abstract}

\section{Introduction}

Unlike for blind or deaf people, it is quite difficult to identify requirements for users with dyslexia, as they are very individual. The dyslexics' inability to decode information is socially restrictive as much as the inability of visually impaired to read the information (Deibel, 2006). For more, missing one sense is balanced by higher sensitivity of other senses. But dyslexics do not miss a sense.

According to psycho-linguistic studies (Marshall and Newcombe, 1973; Friedman et al., 2012), the words in text should not contain more letters (or letters close to each other) that are visually similar. It counts letters like $b, p, d, o, q$ etc. Also, dyslexics find very hard encoding words that are too long for them. Such a word should be broken up by linguistic or visual syllable, depending on the order of problemati $\theta$ symbols. In Czech language it might be: nej-rozši-ře-něj-ši instead of nejrozšířenější ("the most widely used", by linguistic syllable, too long word), kap-oun instead of ka-poun etc. ("fish", visually). The finding, reported in Proceedings of the National Academy of Sciences (Siok et al., 2008) surprisingly shows that there is significant difference in ability to decode words in different languages.

\section{Related Work}

The main elements causing reading inability dwells in visual attention deficit and letter concentration, both based in neural cognition. Research that was done with eye tracker shows that at least one third of probands have difficulties with catching text with eyes (Bellocchi et al., 2013). The same results are indicated in independent study of Laboratory for visual Learning at the Smithsonian Astrophysical Observatory (Schneps et al., 2013).

For instance mobile application American Wordspeller \& Phonetic Dictionary helps users to check their writing and converts phonetic spelling into the proper one. Other software that use text to speech conversion, so that users do not have to deal with visual matter, are Web Reader and CapturaTalk. In past year, IDEAL, the e-book reader was introduced by Rello (2012). Anyway, this application is not a solution for modifying too long words or words with a combination of wrong letters. Moreover, Czech language is too complicated to get by with IDEAL application.

Most of the applications use text to speech conversion approach for its usefulness and simplicity. However, reading should not be avoided by dyslexics. The research study 
conducted by experts from the Institute of Education, University of London shows that reading strenghts attention, brain cognition and information processing over time (Battye and Rainsberry, 2013). Therefore, an application based on text modification is very much needed.

\section{The Complexity of the Czech Language}

Czech language belongs to West Slavic language class. It is inflected language, characterized by a complicated system of declension and conjugation. According to the complexity and a huge vocabulary, the use of applications for instance offering synonyms seems not usable. The declension and conjugation that affects nouns and verbs are grammatical tasks that makes the language and assistive applications most complicated.

\subsection{Declension}

Czech speakers typically refer to the noun cases by number and learn them by means of the question and answer (Šaur, 2004). These numbers do not necessarily correspond to numbered cases in other languages. Nouns, adjectives, pronouns and numbers are declined, there are seven cases over a number of declension models (Tab. 1).

\subsection{Conjugation}

Conjugation applies to verbs. It is a system of grammatically-determined modifications. There are several types of conjugation with more or less complicated rules. A brief overview is in Tab. 2.

Table 1. Declension of Czech nouns.

\begin{tabular}{|l|l|l|}
\hline case & question & title \\
\hline 1 & who/what? & nominative \\
\hline 2 & without whom/what? & genitive \\
\hline 3 & to whom/what? & dative \\
\hline 4 & We see whom/what? & accusative \\
\hline 5 & We address/call & vocative \\
\hline 6 & about whom/what? & locative \\
\hline 7 & with whom/what? & instrumental \\
\hline
\end{tabular}

Table 2. Conjugation of Czech verbs.

\begin{tabular}{|l|l|}
\hline Affection & Types/Classes \\
\hline Infinitive & \\
\hline Participles & Past/Passive \\
\hline Transgressive & \\
\hline Aspect & Perfect/Imperfect \\
\hline Tense & Present/Past/Future \\
\hline Imperative & Singular/Plural \\
\hline Conditionals & Present/Past \\
\hline Passive voice & \\
\hline Reflexive verbs & \\
\hline Negation & \\
\hline Verb Classes & $1-5$ \\
\hline Irregular Verbs & \\
\hline
\end{tabular}

\subsection{Phonetical and Grammatical Syllables}

Czech language, as it was stated, is a quit hard language with many words that follow declension and conjugation. It is still under linguistic concern how to divide syllables in Czech words. There are rules that often do not follow natural feelings of those speaking Czech, respectively those whose Czech is a mother language (Moravec-Robur, 1939). Automatic syllabication is therefore still not flawless and there may be accidental errors that would make dyslexics even more confused. Moreover, phonological syllable does not omit proximity of problematic letters that are hardly decodable.

\section{Methodology}

\subsection{Experimental Approach}

We introduce an application that modifies text according to needs of Czech language environment.

Because the complexity of words depends on individual language, we have to find out the pattern that makes the Czech words hard to decode. We prepare sets of text, one that is original and contains general, non-scientific words, one that divides the letters according to linguistic syllables and the last one that divides the letters in words according to visual syllables. 
Original text:

Pomněnky nekvetou na podzim, ale kvetou pouze z jara.

Phonetic (grammatical) syllables:

Po-mněn-ky nekvetou na pod-zim, ale kvetou pou-ze z jara.

Visual syllables:

Pom-něnky nekvetou na p-o-dzim, ale kvetou p-ouze z jara.

Figure 1 . The three texts read by dyslexics.

Each set has 3 texts which are similar in length. To avoid subjectivity, the proband cannot be tested with same text but we need the texts to be similar as much as possible (Fig. 1). The dyslexics read the three texts, not told what the aim of the experiment is. We measure how fast the dyslexic read each text while the text is read loudly to avoid distorting elements like skipping letters, returning etc. The text with phonological (grammatical) syllables divides the letters only in words they appear in. For exact measurement we use a system reacting on sound so while the dyslexic start reading, the tool starts measuring and stops when the last letter is read.

\subsection{Technical Approach}

Among observation, we need a tool that will detect long words and visually similar letters in the words (according to above mentioned pattern). For modifying the text we use syntactic analyzer that looks for symbols given in a rule that was set according to general text reading problems. For instance, a diagram using cyclical algorithm defines the way to detect such words/letters (Fig. 2). The tool will be built up using state machine.

To the system in Figure 2, if NIS is for example $\geq 2$, the word is possibly hard to decode and has to be broken up into syllables or visually not similar groups of letters. For instance a word "podobná" has more than 2 problematic letters close to each other (there are 5 problematic letters together $-\mathrm{p}+\mathrm{o}+\mathrm{d}+\mathrm{o}+\mathrm{b}$ ) so the letters in the word should be broken up at least after two of such letters (po-do-bná), better after each of the letter (p-o-d-o-bná), depending on preset rule for each language. The same way we detect number of letters contained in a single word.

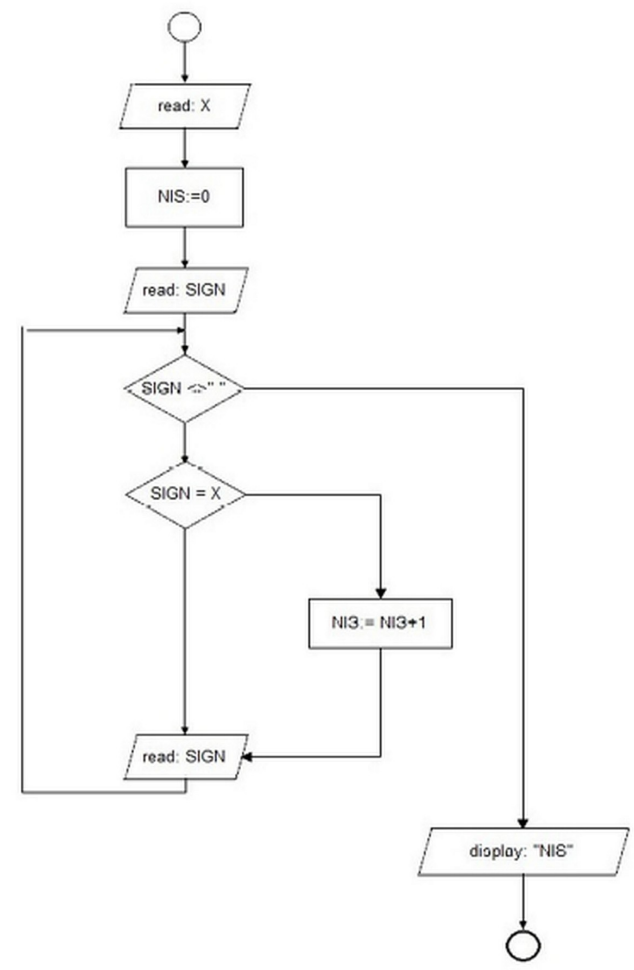

Figure 2. Cyclical algorithm for detecting problematic words.

The only need is to determine what letters, respectively what pair or triplet of letters are problematic for exact language. Once the observation is done, the application we design can be used for any language.

\section{Scientific and Practical Impact}

Based on previous work that was done in area of dyslexic users, within psychological, linguistic and technical studies, we strongly believe that our solution fits best to dyslexics who are very individual users to work with. There are no standards, like WCAG 2.0 for general accessibility that would make web designers and ICT developers to follow such needs. First, they would have to care about accommodating these needs in every single webpage, ebook, ICT tool. It seems impossible, too hard and time consuming. Second, designers and developers have almost none of experience with dyslexic users and self-experience is more than needed when building an assistive technology tool.

We believe that our research, proving explicit problems that dyslexics deal with, will move the 
research in assistive technologies far more ahead. Existing applications are helpful but do not fulfill the needs as much as they could. We add value to actual applications and make the gap between society and people with special needs smaller.

\section{Conclusion}

The outcome of the application is necessary to confront with a sufficient group of dyslexics. It is generally stated that up to one twentieth of population suffers from learning and concentration disabilities, although only some of them are diagnosed (Rello et al., 2013). It would be unethical to stop having interests in problematic with dyslexia.

Our future work will be directed the way of developing proposed tool, to make it usable in ebooks, study materials, and within daily routine needs.

\section{References}

Claire Battye and Meghan Rainsberry, 2013. Reading for pleasure puts children ahead in the classroom, study finds. Institute of Education, University of London.

Guarang Kanvind, Luz Rello and Ricardo BaezaYatez, 2012. IDEAL: a Dyslexic-Friendly eBook Reader. Proceedings of the 14th international ACM SIGACCESS conference on Computers and accessibility. ACM, New York, NY, USA, 205-206.

John C. Marshall and Freda Newcombe, 1973. Patterns of paralexia: A psycholinguistic approach. Journal of Psycholinguistic Research. Kluwer Academic PublishersPlenum Publishers, 2(3):175-199.

Katherine Deibel, 2006. Understanding and supporting the use of accommodating 12 technologies by adult learners with reading disabilities. Accessibility and Computing, ACM SIGACCESS, 86: 32-35.

Luz Rello, Ricardo Baeza-Yates, Stefan Bott and Horacio Saggion, 2013. Simplify or help?: text simplification strategies for people with dyslexia. Proceedings of the 10th International Cross-Disciplinary Conference on Web Accessibility, ACM New York, NY, (15).

Mattheew H. Schneps, Jenny M. Thomson, Chen Chen, Gerhard Sonnert and Marc Pomplun, 2013. E-Readers Are More Effective than Paper for Some with Dyslexia. PLoS ONE 8(9): 75634

Naama Friedmann, Michal Biran and Aviah Gvion, 2012. Patterns of visual dyslexia. Journal of Neuropsychology, 6(1):1-30.

Stefon Bellocchi, Mathilde Muneaux, Mireille Bastien-Toniazzo and Sébastien Ducrot, 2013. I can read it in your eyes: What eye movements tell us about visuo-attentional processes in developmental dyslexia. Research in Developmental Disabilities, 34(1):452-460.

Vladimír Šaur, 2004. Rules of Czech spelling grammar with interpretation. Otto Publishing, Prague.

Wai T. Siok, Zhendong Niu, Zhen Jin, Charles A. Perfetti and Li H. Tan. 2008. A structuralfunctional basis for dyslexia in the cortex of Chinese readers. Massachusetts Institute of Technology, Cambridge, MA, USA, 105(14):5561-5566. 